\title{
The Effect of Media Literacy and Cognitive Ability on Recognition Laptop-Based Media for Children
}

\section{Mainofriwita ${ }^{1}$ \\ Hadiyanto $^{2}$}

Universitas Negeri Padang, Indonesia ${ }^{1,2}$

DOI: https://doi.org/10.21009/JPUD.152.09

Accepted: September 15 $5^{\text {th } 2021 . A p p r o v e d: ~ O c t o b e r ~} 4^{\text {th } 2021}$. Published: November $30^{\text {th }}, 2021$

\begin{abstract}
Education has long been the target of utopian interventions, and with technological interventions, offering to change drastically or even eliminates classroom-based learning, traditional education research needs to focus on introducing technology tools at an early age through media literacy. The purpose of this study was to determine the effect of media literacy and cognitive abilities on the introduction of laptop-based media. This study used a quasi-experimental design involving 46 children. Data collection techniques through tests and data collection tools using statement sheets, which were processed using t-test. The results showed that the experimental class using the original laptop media had a high average value of 86.66 compared to the control class using the imitation laptop media which had a value of 81.66. There is a significant effect of media literacy and cognitive ability on the introduction of laptop-based media in children. On the introduction of laptop-based media in children, media literacy and cognitive capacities can have a big impact. The comparison of the average value of the control and experimental classes demonstrates this. When children are introduced to media via a genuine laptop, they become more excited and engaged in the experimental lesson.
\end{abstract}

Keywords: media literacy, cognitive ability, laptop-based learning media

\footnotetext{
${ }^{1}$ Corresponding Author:

Universitas Negeri Padang

Email: mainofriwita@gmail.com
} 


\section{INTRODUCTION}

Children are in the middle of a large unplanned experiment, surrounded by digital technology that is rarely available (Hirsh-Pasek et al., 2015). Mobile touch screen technology also referred to as tablet technology (Goodwin, 2012) is revolutionizing children's interactive digital experience (Hwang et al., 2015). When the pandemic comes, distance learning for early childhood, often laptops are the choice for online learning. The largest intervention in computer-based learning since 2014 has taken place, the One Laptop per Child (OLPC) project, with 2.5 million laptops in use worldwide. Ames explores how children interpret regular laptop use as "learning" (Ames, 2016).

The paper of Papadakis et al., (2016) reviews empirical research on using four coding applications to help young children develop Computational Thinking and Fluency. The key finding is that all applications have a good impact on the development of computational thinking abilities in youngsters. According to the author, researchers and designers must make difficult decisions in relation to software production to encourage Computational Thinking and Fluency for young children. Researchers must also work in this sector and experiment with novel techniques that capitalize on useful concepts (Papadakis et al., 2021). During a pandemic, it is the right time to improve children's computational thinking skills, because distance learning cause's children to be constantly involved with digital devices, including laptops.

Seftiani (2019) stated that interactive learning was often known as laptop-based learning, especially when distance learning. The use of laptops and gadgets in the learning process is needed to make the learning process interesting. Digital literacy learning can increase children's interest in acquiring knowledge so that children can improve their cognitive abilities and knowledge of media literacy through this laptop-based media. Mobile technology, in combination with interdisciplinary approaches can provide a creative and dynamic learning environment but a didactic approach for early childhood instructors should use, such as developing mixed teaching strategies in a harmoniously enhanced way ICT in the form of computers or tablets (Papadakis et al., 2016b). Although some educators are experienced and knowledgeable technology users, this does not indicate that they fully comprehend the consequences of ICT goods and services when used by young children, and this lack of comprehension may limit their ability to educate their pupils (Ebbeck et al., 2016). While there are hundreds of applications accessible today, selecting the best appropriate educational apps for children is challenging and troublesome for both instructors and educators, according to Papadakis and Kalogiannakis (2017) findings.

In addition to the ability of early childhood educators in their experience of introducing digital technology devices such as laptops to children, several other factors such as media literacy or children's cognitive abilities also influence in recognizing and even using laptops as learning media. The Buckingham study examines the aspects of media literacy and studies on how children's media literacy develops, breaking down the three main categories (access, comprehend, and create) into more precise sub-categories. It also 
points out some of the issues and challenges that come up when attempting to quantify or assess media literacy (Buckingham et al., 2015). Cognitive ability effects to using computers, in which one's performance is redefined and enhanced during intellectual collaboration with the computer, are distinguished from impacts of computers, in which such partnership leaves long-lasting and generalizable cognitive residues (Salomon, 1990).

Problems in the field, it was found that children have not been able to know the parts of a laptop (low digital media literacy) and less varied learning in improving children's cognitive abilities related to digital technology. Based on the background of the problem, this study aims to determine the effect of media literacy and cognitive abilities on the introduction of laptop-based media so that children can follow the development of the current era of technology and information industry.

\section{THEORITICAL STUDY}

\subsection{Media Literacy}

Media literacy in Indonesia became popular in the 2000s as an effort to study media audiences so that they become powerful viewers who live in a world crowded with media. This is also in accordance with the expression of the research results Leena Rantala (2011) suggested media literacy is putting communicators, teachers, scientists, authorities, the technology industry, the media, and civil society together while understanding the challenges of media literacy as part of a global education. This means attributing to media competence the enormous role that is had in a world of global communication and knowing how to take advantage of the potential that the ICTs must improve our world. However, none of this will happen if it is not accepted that this task must be directed by the values and practices of a new humanism that we must all regain and invent. Only this humanism will lead us to peace. The challenges of education in the 21 st century when dealing with children who are digital natives, media literacy is critical (Syarah et al., 2020).

Media literacy is the ability or expertise that a person has to seek, learn, and utilize to be smart in dealing with the media. Syarah et al., (2020) defined media literacy as the ability to derive personal meaning from the visual and linguistic symbols we encounter daily in television, advertising, movies, and other forms of digital media. (Potter, 2010, p. 680) It proposes a media literacy framework based on seven specific skills (analysis, evaluation, grouping, induction, deduction, synthesis, and abstraction) and five sets of knowledge structures (media effects, media content, media industries, real world, and the self). On the other hand, in pedagogy, media literacy may unintentionally activate boomerang effects, in which instruction increases rather than decreases desired outcomes (Hobbs, 2011). Media literacy entails more than merely asking pupils to comprehend information. They must be critical thinkers capable of comprehending and producing in the media culture that surrounds them. The principle of media literacy is to provide skills to individuals who include cognitive, emotional, aesthetic and moral dimensions, and 
media contain the value. Bedford (2021) in his research found that self-confidence is not the same as ability and what we must stimulate in children is the ability to train children's confidence to practice information literacy with laptop media. One of the abilities that can be developed is cognitive ability. The previous study on media literacy which can recognize and understand information comprehensively to realize critical thinking, such as Questions and Answers, analyze and evaluate the information (Juditha, 2013). One of the tools to train children's abilities, namely a laptop, can train children's confidence. Thus, learning carried out using media literacy can train responsiveness, confidence, knowledge, ability, and understanding. Understanding of limited information obtained comprehensively to realize critical thinking in children.

\subsection{Children's Cognitive Ability}

Early childhood is in the golden age so that optimal stimulation will optimize the child's growth and development. All aspects of child development affect each other with other aspects. Therefore, Kindergarten education plays a very important role as a vehicle in ensuring and optimizing children's growth and development. As according to (Colom et al., 2007) that childhood is the basis for continuous learning, health, personality, social behavior, and self-preservation for further development. Early experiences that children have will shape their ability to deal with problems or pressures from the environment. The use of media and teaching materials will determine the success of the teaching and learning process.

Many studies have shown that cognitive abilities such as fluid intelligence (Colom et al., 2007), processing speed (Dodonova \& Dodonov, 2012), and working memory contributes to the prediction of mathematics and reading achievement, which is consistent with the investment theory. Recent meta-analyses, on the other hand, found that fluid intelligence, working memory, and processing speed were only marginally connected with reading and mathematics (Ren et al., 2020). This suggests that general cognitive ability explains about half of the variance in academic success, leaving much of the variance to be explained by additional variables like CT. In addition, it is also disclosed Ferguson et al., (2018) in the results of his research that cognitive abilities in children can be developed by incorporating early childhood development activities into the health system to reach vulnerable children so that there are no problems in behavior, adaptation and other social problems. Thus, cognitive abilities in early childhood are abilities that must be possessed by children to carry out optimal thinking processes and be able to adapt in solving problems faced by children.

\subsection{Laptop Media}

Laptop media is a small technology medium who can be used to introduce technology to children for (Arsyad, 2013) grouping learning media based on technological developments into four classes, including: 1) media produced by print technology, 2) media produced by audio-visual technology, 3) media produced by technology based on laptops, 4) media resulting from a combination of print and laptop technology. A laptop 
or portable computer is a mobile computer that is relatively small and light, weighing 1$6 \mathrm{~kg}$, depending on the size and material specifications of the laptop. The laptop is a small portable and can be carried anywhere easily integrated into the case where it looks like a computer shape that emphasizes ability or easy to carry anywhere. So, a laptop is a small and light device that can be carried everywhere. However, the research results from Seftiani (2019) stated that interactive learning was often known as laptop-based learning. The use of laptops and gadgets in the learning process is needed to make the learning process interesting. Laptop-based technology is a way of producing or delivering materials using microprocessor-based sources.

Other things were also found in the research results of Faigenbaum et al., (2018) conducted interviews on children using laptops that children use laptops to play games by doing interest and character comparisons to watch the games they watch. A previous study found that laptop media promotes student-centered learning (Rusydiyah et al., 2020). Several studies have found that laptop students' computer skills have improved as a result of their use, that laptop students performed better on tasks requiring verbal abilities, and that laptop use in mathematics may reveal a stabilizing effect of laptops in classrooms on students' academic achievement (Trimmel \& Bachmann, 2004). So, laptop-based learning media is an introduction to technology-based learning in delivering material to be effective in helping children's understanding. With activities that are interesting and fun for children, children will quickly accept what is presented by the teacher, so that the ability to introduce media literacy and children's cognitive abilities to laptop-based media will develop well. This study aims to determine how much influence media literacy and cognitive abilities have on the introduction of laptop media in Daud Kholifatulloh Islamic Kindergarten, Padang.

\section{METHOD}

\subsection{Research Approach}

The study's approach is quantitative research using quasi-experimental design (Campbell \& Stanley, 2015).

\subsection{Participants and data collection}

This research was held at Daud Kholifatulloh Islamic Kindergarten, Padang with 46 children in grades B1, B2, and B3. The samples used in class B1 and B2 were due to considerations of number, age, ability level, learning facilities, the same background ability of teachers and recommendations from teachers of both groups and the principal of the Daud Kholifatulloh Islamic Kindergarten, Padang. The sampling technique used is the cluster sampling technique with data collection in this study using pre and post-test. Pre-test carries out before treatment, and post-test carry out after treatment. 


\subsection{Research Design}

The research design of these studies used quasi-experimental pre and post-test design with control and an experimental group selected by the researcher targeted, which is shown in table 1. The research procedure begins with determining the research participants, children in early childhood education institutions. Then the researchers determined the control class and the experimental class to be given treatment. After the pre and post-test, using a t-test to analyze and interpretation were carried out. The data obtained were analyzed quantitatively based on a checklist format for instrument assessment. Before the instrument is used, the instrument is tested first. Furthermore, a trial was conducted the introduction of laptop media. The data obtained were analyzed according to the purpose and truth of the hypothesis. The t-test was carried out when the data was normal and homogeneous to find comparisons.

Table 1. The Pre-test and Post-test of Quasi-Experimental Design

\begin{tabular}{|c|c|c|c|c|}
\hline Class & Pre-Test & Treatment & Post-Test & $\begin{array}{l}\text { Statistica } \\
\text { Analysis }\end{array}$ \\
\hline $\begin{array}{l}\text { Experiment } \\
\text { (introduction of laptop media } \\
\text { with real media) }\end{array}$ & $\mathrm{Y}_{1}$ & $\mathrm{X}_{1}$ & $\mathrm{Y}_{3}$ & t-test \\
\hline $\begin{array}{l}\text { Control } \\
\text { (Introduction of laptop media } \\
\text { with imitation) }\end{array}$ & $\mathrm{Y}_{2}$ & $\mathrm{X}_{2}$ & $\mathrm{Y}_{4}$ & \\
\hline
\end{tabular}

\subsection{Data analysis}

The data obtained in the study were analyzed through several stages of statistical testing. The first stage is to test the normality of the data using the Lilliefors normality test to find out if the data obtained is normal or not. Then the next step is to test the homogeneity using the Bartlett test to find out the data obtained are homogeneous. After performing the normality and homogeneity tests, the next step is to perform a t-test, namely a type of statistical test used to compare the means of two groups in a quasiexperimental design. After knowing the results of the t-test, data interpretation and conclusions were drawn.

\section{RESULT AND DISCUSSION}

\subsection{Result}

\subsubsection{Pre-test and Post-test result}

Data were analyzed using t-test to test the improvement in the experimental class and control class before and after being given treatment. 
Table 2. Recapitulation of Pre-test Results

\begin{tabular}{lcc}
\hline \multirow{2}{*}{ Variable } & \multicolumn{2}{c}{ Media Introduction } \\
\cline { 2 - 3 } & Experiment Class & Control Class \\
\hline $\mathrm{N}$ & 15 & 15 \\
The highest score & 75 & 68,75 \\
Lowest value & 50 & 50 \\
Total value & 918,75 & 868,75 \\
Average & $\mathbf{6 1 , 2 5}$ & $\mathbf{5 7 , 9 1}$ \\
$\mathrm{SD}$ & 7,79 & 6,64 \\
$\mathrm{SD}^{2}$ & 60,68 & 44,08 \\
\hline
\end{tabular}

Thus, the results obtained by the experimental class and the control class in the pre-test have the same ability.

Table 3. Recapitulation of Post-test Results

\begin{tabular}{lcc}
\hline \multirow{2}{*}{ Variable } & \multicolumn{2}{c}{ Media Introduction } \\
\cline { 2 - 3 } & Experiment Class & Control Class \\
\hline $\mathrm{N}$ & 15 & 15 \\
The highest score & 93,75 & 87,50 \\
Lowest value & 75 & 75 \\
Total value & 1300 & 1225 \\
Average & $\mathbf{8 6 , 6 6}$ & $\mathbf{8 1 , 6 6}$ \\
$\mathrm{SD}$ & 8,68 & 7,76 \\
$\mathrm{SD}^{2}$ & 75,43 & 60,21 \\
\hline
\end{tabular}

Thus, the results obtained by the experimental class and the control class there are significant changes.

\subsubsection{Pre-test data analysis}

This normality test used the Lilliefors test as stated in the data analysis technique. Analysis of normality in the experimental and control classes.

Table 4. Lilliefors Normality Test Results (pre-test)

\begin{tabular}{llllll}
\hline Class & $\mathbf{N}$ & $\mathbf{A}$ & $\mathbf{L}$ & $\mathbf{L}$ & Information \\
\hline Experiment & 15 & 0,05 & 0,1704 & 0,220 & Normal \\
Control & 15 & 0,05 & 0,213 & 0,220 & Normal \\
\hline
\end{tabular}

Table 5. Homogeneity test results using the Bartlett test (pre-test)

\begin{tabular}{lllll}
\hline Class & $\mathbf{A}$ & $\boldsymbol{X}^{\mathbf{2}}$ value & $\boldsymbol{X}_{\text {table }}$ & Conclusion \\
\hline $\begin{array}{l}\text { Experiment } \\
\text { Control }\end{array}$ & 0,05 & 0,5257 & 3,841 & Homogenous \\
\hline
\end{tabular}

\subsubsection{Post-test data analysis}

Table 6. Lilliefors Normality Test Result

\begin{tabular}{llllll}
\hline Class & $\mathbf{N}$ & $\mathbf{A}$ & $\mathbf{L}$ & $\mathbf{L}$ & Information \\
\hline Experiment & 15 & 0,05 & 0,1267 & 0,220 & Normal \\
Control & 15 & 0,05 & 0,2019 & 0,220 & Normal \\
\hline
\end{tabular}


Table 7. Homogeneity test results using the Bartlett test (pos-test)

\begin{tabular}{lcccl}
\hline Class & $\mathbf{A}$ & $\boldsymbol{X}_{\text {value }}^{2}$ & $\boldsymbol{X}_{\text {table }}$ & Conclusion \\
\hline $\begin{array}{l}\text { Experiment } \\
\text { Control }\end{array}$ & 0,05 & 0,5257 & 3,841 & Homogenous \\
\hline
\end{tabular}

Table 8. Calculation Results of t-test

\begin{tabular}{lccccc}
\hline \multicolumn{1}{c}{ Class } & $\mathbf{N}$ & $\begin{array}{c}\text { Results } \\
\text { Average }\end{array}$ & tvalue & $\begin{array}{c}\text { ttable } \\
\boldsymbol{\alpha ~ 0 , 0 5}\end{array}$ & Decision \\
\hline Experiment & 15 & 86,66 & 2,325 & 2,04841 & Reject $\mathrm{H}_{0}$ \\
Control & 15 & 81,66 & & \\
\hline
\end{tabular}

Thus, the hypothesis Ha is accepted or $\mathrm{H} 0$ is rejected. It can be concluded that there is a significant difference between the post-test results of children in the experimental class and the control class in introducing laptop media. After calculating the pre-test and posttest values of the experimental and control classes, a comparison will be made between the pre-test and post-test values.

Table 9. Comparison of Calculation Results of Pre-test Scores and Post-test Values

\begin{tabular}{lllll}
\hline Variable & Pre-test & & Post-test & \\
\cline { 2 - 5 } & Experiment & Control & Experiment & Control \\
\hline The highest score & 75 & 68,75 & 93,75 & 87,5 \\
Lowest value & 50 & 50 & 75 & 75 \\
Average & 61,25 & 57,91 & 86,66 & 81,66 \\
\hline
\end{tabular}

So, it can be concluded that the ability of media literacy and cognitive ability to the introduction of laptop-based media after being given treatment has a significant change. Changes occur where the treatment given using the original laptop media is more influential than the artificial laptop media. This can be seen from the average achieved by the children, the experimental class 86.66, and the control class 81.66. So, the results obtained are that there is a significant effect of media literacy and cognitive ability on the introduction of laptop-based media in Daud Kholifatulloh Kindergarten, Padang.

\subsection{Discussion}

The results of the data obtained show that the experimental class using the original laptop media has a high average of 86.66 compared to the control class using the artificial laptop media has a value of 81.66. It is found that the t-count (3.08024) > t-table (2.04841) indicates that there are significant effect of media literacy and cognitive ability on the introduction of laptop-based media in children. This is in accordance with Kellner and Share's (2007) explanation, which states that critical media literacy broadens the definition of literacy to embrace other types of mass communication and popular culture, while also increasing the ability of education to assess critically the relationship between media and audiences, information, and power. This requires an aptitude for analyzing the 
codes and conventions of media, such as laptops, as well as the ability to discern the various meanings and messages created by media texts. The finding of a significant influence in this study also confirms Kellner and Share's (2007) opinion that children with media literacy can distinguish and analyze media content, critically examine media forms, explore the impact, and use of media, utilize media wisely, and create alternative media.

The findings of the research conducted by researchers through observation, interviews, and documentation show that children have not been able to know the part of laptops and learning is less varied in increasing media literacy knowledge and children's cognitive abilities. Thus, the achievement of children's abilities has not developed optimally. Therefore, the current development of technology and information, researchers have found solutions to improve media literacy and cognitive abilities in Daud Kholifatulloh Islamic Kindergarten children in Padang using laptop-based media introduction. The research was carried out by conducting control class activities using imitation laptop media and experimental classes using original laptop media.

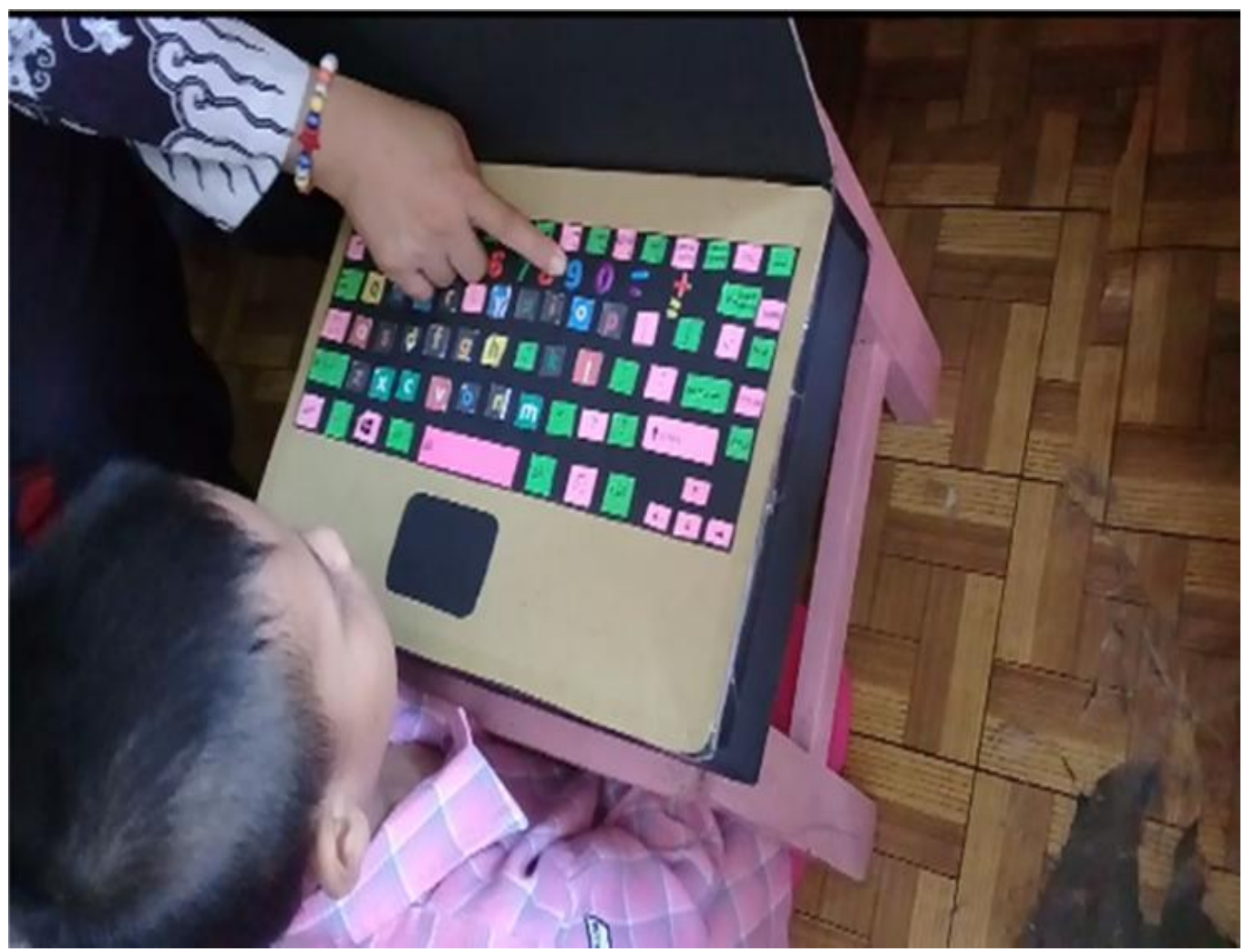

Figure 1. Research in the control class using imitation laptop media 


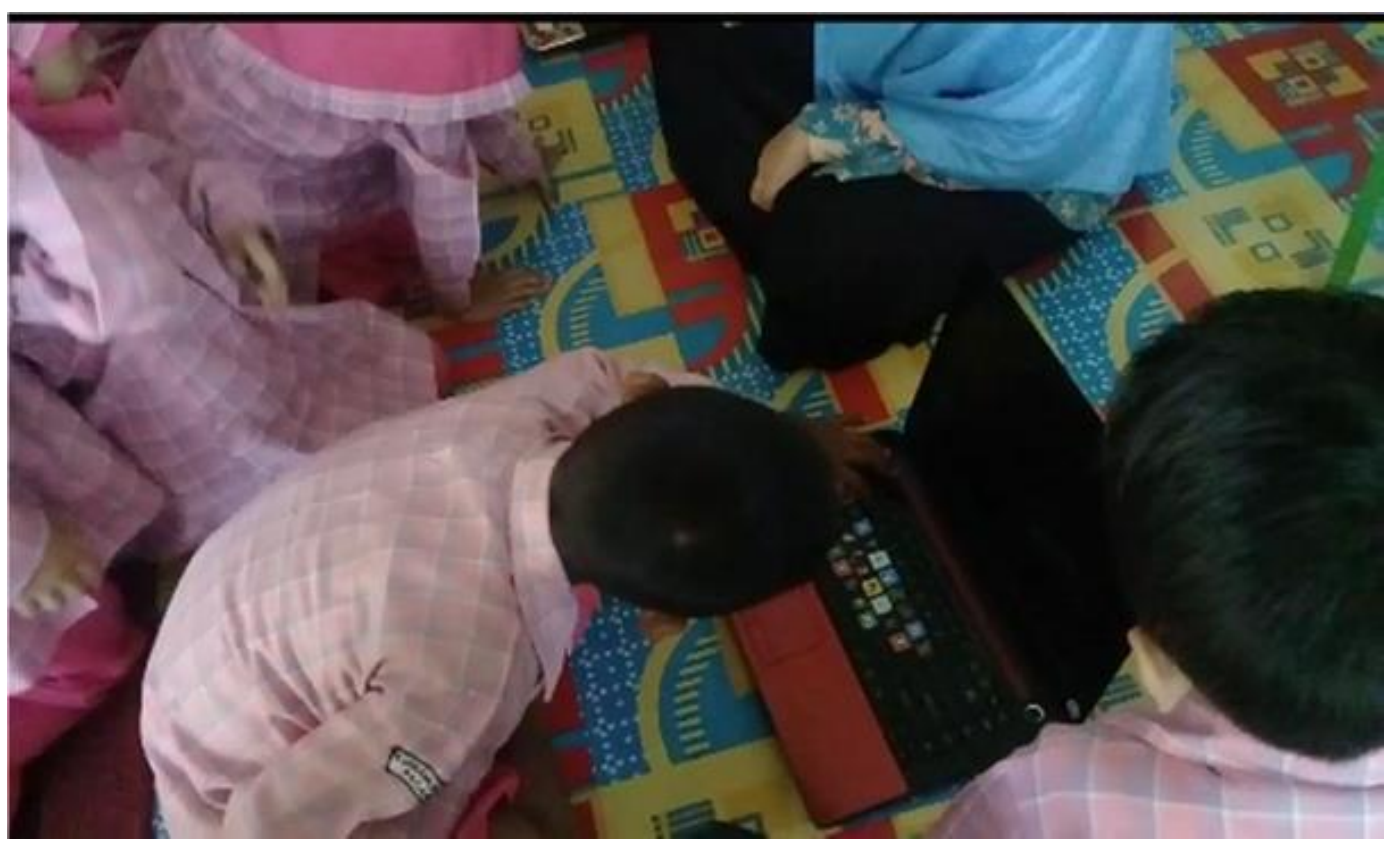

Figure 2. Research using original laptop media

The data obtained from the pre-test, and post-test were then analyzed. Write the researcher's own instrument. The data analysis technique used is the t-test. However, before that, the normality test and homogeneity test were carried out first. Based on the results of the study, it was found that the implementation of learning through laptop media for the introduction of media literacy and improving cognitive abilities, made children more enthusiastic in learning. During learning activities, children focus on the activities carried out, so they can develop a good understanding of the cognitive aspects of children. At the time of the study, it was seen that the difference between the experimental class, and the control class was related to the enthusiasm of children in learning, in the class using the original laptop media. The children were very enthusiastic and in carrying out activities.

Activities that media literacies using original laptop media are more interesting because the media is real, children can see the shape of the laptop. With this very interesting activity, children are enthusiastic so that learning will be meaningful for children, and the introduction of laptop media can develop well. Meanwhile, in the control class that media literacy using an imitation laptop, most of the children are less enthusiastic about doing activities. Prior study on tablet application or another digital device in preschools has shown that serious educational apps can improve a variety of abilities in preschool children. Literacy, geography, art, science, technology, engineering, math, computational thinking, and cognitive and social control are some of these (Liu et al., 2021).

This can be seen when the teacher carries out learning the children are very active and very curious. Advances in technology and information that develop in various forms, children must be equipped with knowledge so that children are able to use things according to their benefits. Macias and Choi (2021) argues that modern digital information and communication technology has changed how we live in various ways, 
and we have become dependent on our digital electronic devices to perform the simplest and routine daily tasks. Thus, the media is one that can improve the achievement of learning objectives. Learning media is defined as a means, tool or technology used to convey messages from sender to recipient and can facilitate the learning process. The purpose of learning media is to arouse children's learning desire, generate learning motivation, facilitate the learning process, and increase the efficiency of the learning process. The characteristics of learning media can be used to anticipate learning conditions that are less effective because they can be independent so that users can use them without the help of others and are also interactive and can help children improve understanding and facilitate interpretation which can ultimately improve children's learning achievement.

The findings in this study of media literacy in the introduction of this laptop add to its own pleasure when learning to know laptop media, and her children can increase their knowledge of the various colors that can be seen from the laptop keyboard which is used as a medium. Like a large laptop from the words lap and top, where lap means "lap," while top means "top." Thus, a laptop can be interpreted as a device that can be carried anywhere and used on the lap. Laptops are small computers that you can take anywhere. Laptops or portable computers are mobile computers that are relatively small and light in weight, weighing from 1-6 kg, depending on the size and material specifications of the laptop. So, a laptop is a small and light device that can be carried anywhere. Laptop components, in principle, are not much different from computer components, only the shape and size are different. Laptop components are smaller in size and can be arranged neatly and compactly so that they are easy to carry and use in various places. Laptop components are made so that they don't heat up quickly and save more power.

While the disadvantages of this laptop are that the price offered is more expensive, the performance of the laptop is poor compared to PCs, the flip cable is easily damaged on the laptop, there is no possibility to upgrade various components in laptops and laptops, including luxury and light items for use. Carried everywhere so that it becomes the target of thieves. So, the advantage of a laptop is that it can be carried everywhere because the laptop is smaller in size, does not waste electricity, can be used as a learning medium, does not require a large space. While the disadvantages of this laptop are the relatively expensive price, the components in it are difficult to upgrade, and the laptop's performance is not satisfactory. Since laptops are not like 'conventional' technological devices such as computers, which require fine motor skills to operate properly and can be challenging for young children, tablets have a simple touch-based interface which makes them suitable for children aged 2 to four years. In the UK, Livingstone et al., (2015) found that children aged 0 to five years were skilled tablet users. Children can browse through apps and take advantage of the capabilities of multimodal devices.

The next findings, media literacy can introduce laptop media in a simple way to children, where children can show the alphabet keys on the keyboard, children can say the number of symbols on the number keys on the keyboard, show the monitor screen and 
children can open and close the laptop monitor screen according to the command teacher. So, a laptop is a small and light device that can be carried anywhere. The advantage of a laptop is that it can be carried everywhere because the laptop is smaller in size, does not waste electricity, can be used as a learning medium, does not require a large space. While the drawbacks of this laptop are the relatively expensive price, the components in it are difficult to upgrade, and the laptop's performance is not satisfactory, the advantages of using a laptop early on are improving verbal and communication skills, increasing personality development, and making time efficient.

The ability to recognize and search can increase the knowledge and ability of children's confidence in the media used, especially in the introduction of laptop media. It is also expressed Bedford (2021) in the results of his research that self-confidence is not the same as ability and what we must stimulate in children is the ability to train children's confidence to be able to practice information literacy with laptop media. In addition, improving the knowledge of media literacy is a competence that can be developed, namely cognitive abilities. The term cognitive has the same meaning as intellectual and cognitive is related to intelligence.

Cognitive is more passive or static while intelligence is more active. Cognitive ability is one aspect of student development related to understanding (knowledge), namely the realm of knowledge, which is all psychological processes related to how individuals learn and think about their environment. In line with that, cognitive ability can also be interpreted as a thinking process, namely the individual's ability to connect, assess, and consider an event or events. Cognitive processes are related to the level of intelligence (intelligence) that marks a person with various interests, especially aimed at learning ideas. Based on revealed by Schaeffer (2021) in the results of his research that cognitive ability is an ability that can be developed when children carry out learning with direct or real objects so that they understand more concepts and are meaningful. The main factors that affect children's cognitive abilities are maturity and experience factors that come from children's interactions with the environment. From interaction with the environment, children will gain experience by using assimilation, accommodation, and being controlled by the principle of balance.

Correspondingly, the findings Zou'bi (2021) revealed that the impact of media literacy is that children can improve critical abilities. The ability to think critically and remember with new knowledge is a child's cognitive ability. Through the introduction of laptopbased media, it affects cognitive abilities. The stimulation or stimulation can be given according to the needs of the child so that the child's growth and development is achieved optimally. Cognitive ability is a thought process to develop the potential or abilities that children must acquire. Thus, learning to recognize laptop-based media can improve children's cognitive abilities in knowing numbers and letters and other symbols. The current progress of science and technology, especially information technology, greatly influences the preparation and implementation of partiality strategies for early childhood. 
The results of hypothesis testing conclude that there is a significant influence of media literacy knowledge and cognitive abilities on the introduction of laptop-based media. Media literacy in the introduction of this laptop adds to its own pleasure when learning to know laptop media, and her children can increase their knowledge of the various colors that can be seen from the laptop keyboard which is used as a medium. Not only cognitive aspects can be developed but also other developmental aspects, likewise, research conducted on Daud Kholifatulloh Padang Kindergarten children because of the implementation of media introduction learning carried out by both classes using original laptop media in the experimental class and artificial laptop media in the control class. Changes found using the original can provide meaningful learning and hands-on experiences for children.

Where the implementation of this media literacy activity can also introduce numbers and letters of the alphabet to children, so that children remember the numbers and letters of the alphabet on the keyboard. The implication of the results of this study is suggested that the introduction of laptop-based media can affect the increase in media literacy knowledge and children's cognitive abilities. The activities use the original laptop media, there are two laptops used. Media literacy activities using a laptop will be tried by each child in turns. With this interesting activity, children are enthusiastic so that learning will be meaningful for children, and the introduction of laptop media can develop well. Efforts to introduce laptop-based media can improve cognitive abilities.

Basically, children aged 5-6 years, the ability to recognize shapes has entered the stage, namely children already can recognize shapes. This can be seen by children being able to mention geometric shapes such as circles, triangles, and squares. Children can show geometric shapes that have been shown by the teacher. The child can group objects and pair objects according to pairs of the same shape. Efforts are made to introduce laptop parts, symbols, numbers, and letters on the keyboard to children, so that children remember, mention, know, demonstrate, think critically, and solve problems. Based on the data analysis conducted, the researcher can conclude that there is an effect of media literacy and cognitive ability on the introduction of laptop-based media in Islamic Kindergarten children Daud Kholifatulloh.

\section{CONCLUSION}

Based on the results of the research found, it can be concluded that there is a significant difference between the introduction of laptop media in the experimental class and the control class in Daud Kholifatulloh Islamic Kindergarten, Padang. Media literacy can be affected by the increase through the introduction of laptop-based media. This is evidenced by the ability to recognize media literacy using original technology tools as a form of learning media so that the ability to search, study, and utilize media must be introduced early. Knowledge of media literacy does not only use laptops but can also be done with other technological media. Children's cognitive abilities can also be influenced by the introduction of laptop-based media. This is proven through laptop media. Children can know numbers, letters, symbols, and laptop parts and their functions. Today's 
technological developments require us to know about technological tools and be able to take advantage of positive things according to their functions. Media literacy and cognitive abilities on the introduction of laptop-based media in children can have a significant influence. This is evidenced by the comparison of the average value of the control class and the experimental class. Children are more enthusiastic and interested in the experimental class by using media introduction using a real laptop.

\section{REFERENCES}

Adams, D., \& Hamm, M. (2001). Literacy in a multimedia age. MA: Christopher- Gordon Publishers.

Ames, M. G. (2016). Learning consumption: Media, literacy, and the legacy of One Laptop per Child. The Information Society, 32(2), 85-97. https://doi.org/10.1080/01972243.2016.1130497

Arsyad. (2013). Media Pembelajaran [Learning Media]. Raja Grafindo Persada.

Bedford, D. (2021). Evaluating confidence in information literacy: A red/amber/green approach. Journal of Information Literacy, 15(1), 96-104. https://doi.org/10.11645/15.1.2833

Buckingham, D., Banaji, S., Burn, A., Carr, D., Cranmer, S., \& Willett, R. (2015). The Media Literacy of Children and Young People (p. 76). Youth and Media Institute of Education. www.ofcom.org.uk

Campbell, D. T., \& Stanley, J. C. (2015). Experimental and Quasi-Experimental Designs for Research. Ravenio Books. https://books.google.co.id/books?id=KCTrCgAAQBAJ

Colom, R., Escorial, S., Shih, P. C., \& Privado, J. (2007). Fluid intelligence, memory span, and temperament difficulties predict academic performance of young adolescents. Personality and Individual Differences, 42(8), 1503-1514. https://doi.org/10.1016/j.paid.2006.10.023

Dodonova, Y. A., \& Dodonov, Y. S. (2012). Processing speed and intelligence as predictors of school achievement: Mediation or unique contribution? Intelligence, 40(2), 163-171. https://doi.org/10.1016/j.intell.2012.01.003 
Ebbeck, M., Yim, H. Y. B., Chan, Y., \& Goh, M. (2016). Singaporean Parents' Views of Their Young Children's Access and Use of Technological Devices. Early Childhood Education Journal, 44(2), 127-134. https://doi.org/10.1007/s10643$015-0695-4$

Faigenbaum, G., Sigman, M., \& Casiraghi, L. P. (2018). Young Children Use Discovery and Creation Significantly More Than Adults for Deciding Ownership. Child Development Research, 2018(4). https://doi.org/10.1155/2018/1517904

Ferguson, B. A., Downey, J. L., Shriver, A. E., Goff, K. L., Ferguson, A. M., \& De Mello, M. C. (2018). Improving Early Childhood Development among Vulnerable Populations: A Pilot Initiative at a Women, Infants, and Children Clinic. Child Development Research, 2018. https://doi.org/10.1155/2018/3943157

Hirsh-Pasek, K., Zosh, J. M., Golinkoff, R. M., Gray, J. H., Robb, M. B., \& Kaufman, J. (2015). Putting Education in "Educational" Apps: Lessons from the Science of Learning. Psychological Science in the Public Interest, 16(1), 3-34. https://doi.org/10.1177/1529100615569721

Hobbs, R. (2011). The state of media literacy: A response to potter. Journal of Broadcasting and Electronic Media, 55(3), 419-430. https://doi.org/10.1080/08838151.2011.597594

Hwang, G.-J., Lai, C.-L., \& Wang, S.-Y. (2015). Seamless flipped learning: A mobile technology-enhanced flipped classroom with effective learning strategies. Journal of Computers in Education, 2(4), 449-473. https://doi.org/10.1007/s40692-015-0043-0

Juditha, C. (2013). Literasi Media pada Anak di Daerah Perbatasan Indonesia dan Timor Leste [Media Literacy for Children in the Border Areas of Indonesia and Timor Leste]. JURNAL IPTEKKOM: Jurnal Ilmu Pengetahuan \& Teknologi Informasi, 15(1), 47. https://doi.org/10.33164/iptekkom.15.1.2013.47-62 
Kaushal S and Singh CK. (2021). Home Stimulation and Cognitive Abilities of Disadvantaged Children. Journal of Scientific Research, 65(1). https://doi.org/DOI: 10.37398/JSR.2021.650413

Kellner, D., \& Share, J. (2007). Critical Media Literacy, Democracy, and the Reconstruction of Education. Peter Lang Publishing. www.centerxgseis.ucla.edu Leena Rantala. (2011). Finnish Media Literacy Education Policies and Best Practices in Early Childhood Education and Care Since 2004. The National Association for Media Literacy Education's Journal of Media Literacy Education, 3, 123-133.

Liu, W., Tan, L., Huang, D., Chen, N., \& Liu, F. (2021). When Preschoolers Use Tablets: The Effect of Educational Serious Games on Children's Attention Development. International Journal of Human-Computer Interaction, 37(3), 234-248. https://doi.org/10.1080/10447318.2020.1818999

Livingstone, S., Marsh, J., Plowman, L., \& Fletcher-Watson, B. (2015). Young Children (0-8) and Digital Technology (p. 55). Joint Research Centre. http://publications.jrc.ec.europa.eu/repository/handle/JRC93239

Macias, C., \& Choi, K. (2021). Preschoolers' beliefs about media technologies: The role of family income. Human Behavior and Emerging Technologies, 3(4), 572-584. https://doi.org/10.1002/hbe2.278

Papadakis, S., Kalogianakis, M., Sifaki, E., \& Monnier, A. (2021). Editorial: The Impact of Smart Screen Technologies and Accompanied Apps on Young Children Learning and Developmental Outcomes. Frontiers in Education, 6, 790534. https://doi.org/10.3389/feduc.2021.790534

Papadakis, S., \& Kalogiannakis, M. (2017). Mobile educational applications for children: What educators and parents need to know. Int. J. Mobile Learning and Organisation, 11(3), 22.

Papadakis, S., Kalogiannakis, M., \& Zaranis, N. (2016a). Developing fundamental programming concepts and computational thinking with ScratchJr in preschool 
education: A case study. International Journal of Mobile Learning and Organisation, 10(3), 187. https://doi.org/10.1504/IJMLO.2016.077867

Papadakis, S., Kalogiannakis, M., \& Zaranis, N. (2016b). Comparing Tablets and PCs in teaching Mathematics: An attempt to improve Mathematics Competence in Early Childhood Education. Preschool and Primary Education, 4(2), 241. https://doi.org/10.12681/ppej.8779

Potter, W. J. (2010). The state of media literacy. Journal of Broadcasting and Electronic Media, 54(4), 675-696. https://doi.org/10.1080/08838151.2011.521462

Ren, X., Tong, Y., Peng, P., \& Wang, T. (2020). Critical thinking predicts academic performance beyond general cognitive ability: Evidence from adults and children. Intelligence, 82, 101487. https://doi.org/10.1016/j.intell.2020.101487

Rusydiyah, E. F., Ummah, F. S., \& Mudlofir, A. (2020). The Implementation of Laptop Mobile in the Teaching-Learning Process in Islamic Boarding School. TARBIYA: Journal of Education in Muslim Society, 7(1), 67-77. https://doi.org/10.15408/tjems.v7i1.13650

Salomon, G. (1990). Cognitive Effects with and Of Computer Technology. Communication Research, $\quad$ 17(1), 26-44. https://doi.org/10.1177/009365090017001002

Schaeffer, J. (2021). The influence of cognitive abilities on article choice and scrambling performance in Dutch-speaking children with autism. Language Acquisition, 28(2), 166-194. https://doi.org/10.1080/10489223.2020.1724293

Seftiani, I. (2019). Alat Evaluasi Pembelajaran Interaktif Kahoot pada Mata Pelajaran Bahasa Indonesia di Era Revolusi Industri [Kahoot Interactive Learning Evaluation Tool for Indonesian Language Subjects in the Industrial Revolution Era] 4. 0. Prosiding Seminar Nasional Bulan Bahasa (Semiba) 2019, 284-291.

Syarah, E. S., Mayuni, I., \& Dhieni, N. (2020). Understanding Teacher's Perspectives in Media Literacy Education as an Empowerment Instrument of Blended Learning 
in Early Childhood Classroom. JPUD - Jurnal Pendidikan Usia Dini, 14(2), 201214. https://doi.org/10.21009/JPUD.142.01

Trimmel, M., \& Bachmann, J. (2004). Cognitive, social, motivational and health aspects of students in laptop classrooms. Journal of Computer Assisted Learning, 20(2), 151-158. https://doi.org/10.1111/j.1365-2729.2004.00076.x

Zou'bi, R. A.-. (2021). The impact of media and information literacy on acquiring the critical thinking skill by the educational faculty's students. Thinking Skills and Creativity, 39, 100782. https://doi.org/10.1016/j.tsc.2020.100782 